This abstract presents reflections on recruiting and involving South Asian patients with rheumatoid arthritis (RA) in research; it draws on the first author's experiences of leading a qualitative study which explored South Asian patients' perceptions of communicating the risk of developing RA with relatives. RA is a chronic inflammatory condition that may lead to long-term disability and co-morbidities. First-degree relatives are at increased risk. Access to this group is dependent on the co-operation of patients with RA; it is therefore important to understand patients' perceptions of risk and their willingness to communicate risk with relatives. Fifteen patients of South Asian origin were recruited in a secondary rheumatology clinic. Participants were also approached to act as patient research partners (PRPs) and help with interpreting and validating the data.

We adopted a culturally competent approach: cultural competency entails understanding that socio-cultural factors influence patient participation in research and ensures that these influences do not become a basis for exclusion. South Asian groups are frequently considered 'hard to reach' - a label which suggests a lack of engagement on their part rather than institutional barriers. The conventional approach, commonly adopted by qualitative researchers, can serve to exclude people by, for example, including only people who speak English. As a researcher from a South Asian background, the author found her shared identity, languages and experiences helped to facilitate recruitment, build rapport and involve participants as PRPs.

\section{PP HEARING THE VOICES OF MARGINALISED GROUPS: REFLECTIONS ON RECRUITING AND INVOLVING BRITISH SOUTH ASIAN PATIENTS WITH RHEUMATOID ARTHRITIS IN A QUALITATIVE STUDY}

ZP Latif, ${ }^{1,2,3 *}$ RJ Stack 4 . ${ }^{1}$ College of Medical and Dental Sciences, Institute of Inflammation and Ageing, University of Birmingham, UK; ${ }^{2}$ Sandwell and West Birmingham Hospitals NHS Trust, UK; ${ }^{3}$ College of Medicine, Biological Sciences and Psychology, Department of Health Sciences, University of Leicester, UK; ${ }^{4}$ The Division of Psychology, Nottingham Trent University, UK 